\title{
ENTREVISTA CON ABEL POSSE *
}

\author{
POR \\ MAGDALENA GARCIA PINTO \\ University of Missouri-Columbia
}

MGP: ¿Cuándo empezaste a escribir?

AP: Desde muy chico consideraba que mi destino era ser escritor a los catorce o quince años. Cuando todavía no había terminado el secundario ya tenía una vocación firme. En la universidad ya pensaba que estudiar era quitarle el tiempo al placer de leer, de vagar en los cafés con mis amigos; ésa fue la gran formación que daba Buenos Aires en esa época. Dentro de todo lo malo, tenía algo muy bueno: una formación muy exigente de los escritores; por eso salen esos escritores tan universales, que no hay en otras partes del mundo, como Cortázar, como Borges, como Bioy Casares, hombres de una formación muy total, pero había muchos escritores y todos tenían que saber todo en esa época. Un escritor joven tenía que saber perfectamente quién era Lao Tse, qué era el budismo; tenía que tener una noción bien clara de Freud, porque era el tema de íos encuentros en los cafés, una pasión casi argentina de Freud; también se hablaba de Nietzsche, de filosofía alemana, de la literatura del mundo; se conocía mucho la literatura rusa y francesa. Esa maravilla de la universidad popular de Buenos Aires, esa universidad literaria de la noche de esa ciudad que conoció una especie de apogeo que yo creo que ya se perdió, pero que le dio a Buenos Aires su bien y su mal.

Al mismo tiempo creó un mundo cerrado con las editoriales, se volvió las espaldas al interior y se agotaron en un culteranismo porque después de Borges y Bioy hay una especie de culteranismo que continúa entre los jóvenes de ahora. Casi todos escriben igual dentro de una moda porque es un medio literario que los produce.

* Abel Posse, escritor y diplomático argentino, fue ganador del Premio Internacional de Novela Rómulo Gallegos correspondiente al año 1987. 
MGP: ¿Cuándo decidiste publicar tu primer trabajo?

AP: Aunque empecé temprano a escribir, publiqué tardíamente y por influencia de Carlos Mastronardi y de Conrado Nalé Roxlo, quienes, cuando cayó Perón en el año 1955, dirigían un diario que tenía un suplemento literario muy activo, muy porteño, que era el diario El Mundo. Por invitación publiqué mi primer poema y unos cuentos, pero yo quería escribir novelas, y empecé una larguísima, que nunca terminé. Durante mi estadía en París escribí mucho, pero no publiqué nada hasta más allá de mis treinta años.

MGP: ¿Por qué decidiste ir a París? ¿Tal vez siguiendo la trayectoria casi obligada del escritor americano?

AP: Sí, era casi la formación obligada. El escritor porteño o criado en esta ciudad tenía todos los esquemas de valores relacionados con Europa: el arte, el cine, la literatura. En todo estamos ligados a Europa, y Buenos Aires es una puerta tremenda hacia el continente.

MGP: ¿Qué impacto tuvo tu estancia en París para tu desarrollo?

AP: Yo tenía veinticuatro años y París era el gran centro cultural. Todos mis esquemas de valores estaban relacionados con Europa. Nunca se me ocurrió ir a los Estados Unidos; pero, más grave aún, tampoco se me había ocurrido ir al Brasil.

MGP: ¿Era la visión cultural que imperaba entonces en Buenos Aires?

AP: Sí. Pero ahora esto cambió. Después, hasta por razones económicas, los jóvenes empezaron a viajar por América y después llegaban a otras partes. En esa época se tomaba un barco argentino muy barato y se iba directamente a París. Había un medio muy rico ahí. No sé cómo me influyó, porque siempre cré́ que mi vida literaria era un poco marginal de la cosa exterior; es mucho más profundo mi mecanismo de influencias.

MGP: De los que estaban en París, ¿a quiénes tuviste oportunidad de conocer?

AP: Estaban Cortázar, Mario Trejo; estaba vivo Petorutti. Conocí a mucha gente: a Sartre, a Neruda. Sartre acababa de venir de Cuba y tenía una serie de interpretaciones francesas de la realidad americana, y las decía. Era sin duda el centro. En mi primera novela está París porque es casi un poco el prólogo de la explosión, el clima del 68, y la escribí principalmente en París entre 1962 y 1963, y la terminé en Moscú en 1967. Son los años de fermento. También conocí revolucionarios, entre ellos a Raúl Quiroga de la Vega, que era gente que se lanzó a esa gran explosión. Era un mundo muy intenso, con unas ideas muy distintas de las de hoy; se creía que al mundo había que hacerlo.

MGP: ¿Compartías con ellos su posición ideológica?

AP: No, yo era anarquista independiente, como todo escritor. En mí 
siempre prevaleció el escritor en todas las decisiones, pero sí tenía una gran simpatía y comprendía lo que pasaba; no era un afiliado, pero estaba cerca de todo eso. A todo ese mundo yo lo conocí como un gran movimiento cultural, no solamente en su dimensión política. A mí me interesaba como el gran fermento de una cosa, de una inquietud americana que todavía sobrevive, de un continente en formación como se ve casi geológicamente, la tierra cuando bulle, un volcán. Así veo yo a América desde Europa. Eso influyó y está metida para siempre en mí esa visión.

MGP: ¿Es como si América surgiera, casi naciera en tu conciencia, cuando te vas a Europa?

AP: Sí, así es. Rectierdo cierta frase de Ricardo Güiraldes, que decía que, pese a las críticas, la distancia sirve para revelar la realidad nuestra. Dijo esto mientras escribía Don Segundo Sombra en París.

Esta experiencia y revelación pasa a ser parte de nuestra conciencia americana cuando salimos de nuestros países. No lo vemos bien cuando estamos inmersos en él. Es una realización que compartimos muchos latinoamericanos, pero son sólo los privilegiados por la escritura los que pueden articular esta visión para el resto.

MGP: ¿Qué literatura te interesaba en tu primera época de escritor?

AP: Leí Faulkner, Dos Passos, Thomas Wolfe, Melville y los grandes clásicos que hacen su obra antes del 45, sobre todo Faulkner, que es una influencia muy grande en mí y en todos los escritores de América y de Italia. Es cuando la literatura norteamericana influye fuertemente en el mundo. Un hombre como Truman Capote no puede decirnos nada a nosotros, nada más que simpáticas decadencias, a pesar de que es un enorme escritor; pero Styron es un Dostoiesvki envejecido, y Saul Bellow, que nos parece un escandaloso melodramático, actualista. Esa literatura no nos interesa para nada; es toda menor al lado de los grandes.

MGP: ¿De qué manera particular te interesa Faulkner? ¿Qué encuentras en su narrativa de importancia para vos, para tu escritura?

AP: Me interesaba estéticamente porque yo tengo mi interpretación de la influencia de este escritor en América Latina y en Italia. El tocó, sin saberlo, una fibra tremendamente latina. Faulkner es una especie de latino secreto, así como Borges dijo que Shakespeare debería haber sido italiano por su fuerza expresiva. La fuerza de Faulkner reside en 1a presencia de la tierra, la geografía, la siesta, el calor, el subdesarrollo, el hombre, el sudor, las grandes casas, las tradiciones. El sur era nuestro puente, nuestro profundo puente con los Estados Unidos, un Estados Unidos que inmediatamente después se hacía remoto. Y después venía Europa. Nunca pudimos penetrar culturalmente el norte con afecto, lo veíamos distante, ajeno, no nos interesaba. Fue todo eso, la revelación de la huma- 
nidad profunda y de una fuerza estética que está en el lenguaje nuestro. Faulkner está más cerca de Carpentier o de Borges que de Bellow. Está más en esa línea de creación sofisticada del lenguaje, tiene gravedad. Es las dos cosas: el mundo de lo real, de lo telúrico, los instintos y al mismo tiempo un sentido estético de enorme artista.

MGP: En tu formación literaria, ¿cuáles son otros escritores que reconocerías como tus mentores, a los que te han enseñado algunos secretos de la creación literaria?

AP: Los rusos y ciertos franceses, o los grandes disidentes del discurso oficial francés, y yo los llamaría disidentes a los que arrancan con Rimbaud, como Proust, Céline y Jean Gênet. Ese es un lenguaje de una tremenda fuerza creativa y es un lenguaje que se crea contra un discurso oficial opresor como es la lengua francesa normal. En la ideología también influyen los grandes activistas no porque eran filósofos importantes, sino porque eran catalizadores culturales y alentaban corrientes más profundas del pensamiento alemán, del pensamiento sociológico, y me estoy refiriendo a Sartre y Camus. En esos años, estos dos pensadores eran muy importantes, no porque en sí tuvieran mucha importancia filosófica, porque no la tenían, sino porque eran grandes provocadores y difusores de cultura.

MGP: ... y cuestionadores de un orden y de un pensamiento europeo que tiene mucha influencia y amplia difusión. Pero volvamos a los rusos...

AP: Fueron, claro, los grandes: Dostoievski, Chejov, Pushkin. Influyen en todos nosotros. Creo que todos los escritores de América conocen bien a los narradores rusos, y después está ese gran ruso, ese crucero extraordinario que es Vladimir Nabokov.

MGP: ¿Por qué no has nombrado a ningún latinoamericano todavía?

AP: Porque en esa época todavía no había influencia de ellos, pero esa literatura crece con mucha fuerza. Hace veinticinco años todavía no había eclosionado eso que ya estaba en Borges, en Arguedas, en Asturias, pero que hace eclosión en una segunda generación, y hoy día la literatura latinoamericana es un universo autónomo porque se influencia a sí misma. Hoy día tengo más placer leyendo a Lezama Lima que a cualquier escritor francés o inglés.

AP: Salvo Nabokov o Faulkner, yo no encuentro placer en la literatura anglosajona actual. Pero esto ya me había pasado en Francia, donde viví ocho años, y en Italia, donde viví seis años. Me pasó de no encontrar ni en España misma una literatura como la latinoamericana. Lo que ocurre es que esta literatura tiene desde la zona culterana, sofisticada de Borges hasta Guimarães Rosa y Lezama Lima; es un arco que incluye la novelística realista, la narración tan bien hecha como la de Vargas Llosa, la fantasía extraordinaria del vuelo del lenguaje de García Márquez. Es 
una literatura muy rica; incluye lo grave y lo frivolo estético. Porque lo grave, si uno ve la intensidad de Rulfo, es casi mayor que la de Faulkner en sus momentos mayores. Si uno toma la intensidad de Arguedas en Los ríos profundos, es realmente una obra de la tierra, del yo profundo del hombre, de la ruptura, de la quiebra, del abismo, o sea, es una literatura que tiene casi todas las zonas y llega a esa explosión del lujo del lenguaje que es el barroco cubano, con Lezama Lima, Severo Sarduy y Carpentier. Por eso digo que la madurez de una literatura, su gran momento, es cuando se influencia a sí misma. Hoy día un escritor latinoamericano lee a sus propios autores, y en mis primeros años de formación eso no había ocurrido.

MGP: Naturalmente, este punto es un aspecto fundamental para nuestra literatura. ¿Cuándo descubres las obras de tu propia literatura?

AP: A medida que yo iba escribiendo, los grandes monstruos venían avanzando antes que yo, y están ahí, a un paso. Estaba Borges, pero a Mallea ya lo discutíamos: nos parecía cursi, pesado, europeísta. A Borges no se le discutía porque era un episodio absolutamente estético. Luego, esa literatura se define y es un universo muy rico y muy enriquecedor, porque el escritor se forma en su propio medio.

MGP: Acabas de publicar una nota sobre Borges y Carpentier en $L a$ Nación, que revela un interés particular por la literatura cubana.

AP: Me interesa la literatura formalista cubana como la de Severo Sarduy; Carpentier es un gran maestro, pero mi ídolo es Lezama Lima. Me parece que es el que llegó más lejos como locura, como lenguaje, como uso de la cultura de una manera absolutamente libre. El y Borges, en este punto, son casi el paroxismo.

MGP: Sarduy es más oscuro, más opaco y hasta hermético. ¿Su lectura es más difícil?

AP: Sí, Sarduy no tiene la transparencia de la prosa de Lezama, es más cerrado y hasta casi impenetrable. Lezama Lima arriesga la claridad. Es el punto máximo desde el siglo xvi de la lengua española, y Borges, por la precisión, por cierta renovación del español, de su capacidad expresiva; pero no alcanza el esplendor de Lezama en todo caso.

MGP: ¿Has escrito crítica literaria?

AP: Muy poco. Hago escritos cortos, como ese al que te referiste recién. Notas. A veces he escrito con más cuidado, pero muy poco.

MGP: ¿Dirías que reconoces dos o tres maestros o, más bien, que tu literatura se ha ido desarrollando paultinamente, sin influencias particuiares?

AP: Soy un ladrón tan amplio, que no puedo decir que he robado un solo negocio; pero, en todo caso, esos mentores serían los cubanos. Me 
inicié escribiendo novelas en un sentido porteño, y en un determinado momento tuve la exacta sensación de que yo no estaba dentro de mi voz. Me sentía incómodo, como cuando uno está en un lugar que no le gusta. La única formación de un escritor, creo yo, es encontrar su voz, que su ser coincida con una voz más o menos verdadera de las tres o cuatro que alcanza a impostar cuando escribe. Escribir es una impostura. $Y$ hay momentos de esa impostura que son más legítimos, y ese caer en el propio lenguaje es un momento de satori, como diría un budista zen, de revelación, donde todo un juego de intuiciones se da en ese preciso instante a través de la palabra. Para mí, eso no ocurría. Yo escribía fuera de mí, como un escritor porteño. Escribí dos o tres novelas así, entre las que están Los bogavantes y La boca del tigre. Hasta que en Perú empecé un cambio y pasé a lo contrario. Tenía, además, un peso gravísimo, que era la formación ideológica en el sentido de que todo escritor porteño, argentino, por ejemplo, de la línea de Sábato, la tiene. Es un escritor que se forma más con ideas sobre la vida que con experiencia directa o la estética del vida y del lenguaje. Eso es un problema de la literatura de Buenos Aires, que puede llegar a dar un Borges, o que puede arruinarse en el camino, y que no sirve para nada. Yo en algún momento fui consciente de eso y luché contra mí mismo. Yo creo que hay un momento en la formación de un escritor donde es necesario aplicar el principio flaubertiano de que hay que ir contra el impulso de lo que ya se logró. El dice: «Jamais profiter des élans acquis», y ésa es la guerra secreta de un escritor en su formación: ir hacia su propia voz, destruyendo su facilidad, sus padres y el Superego. Y ahí viene el gran combate. Yo lo hice a través de los cubanos. Yo leía lo que no podía escribir, en suma. En un determinado momento me reciclé, como ahora hacen con los ingenieros, que los mandan a estudiar a una universidad, ya grandes, hombres de cuarenta años, que están haciendo de nuevo todo. Bueno, así yo hice conmigo, pero con mucho coraje, lo debo decir. Yo sabía que no estaba en mi voz. Después del Perú, y después de muchos años, porque yo escribía un libro cada seis o siete años. Desde 1971 a 1978 no publiqué nada porque estaba en este proceso. Tardo siete años. En ese tiempo tuve la suerte de que me mandaran a Venecia, que es en sí misma como Lezama Lima, como Sarduy. En Venecia se corroboró esto. Y tuve un larguísimo trabajo de lenguaje para crear la novela Daimón, este nuevo ritmo, donde yo creo que estoy yo, lo que más vale de mí.

MPG: ¿Cómo ves en retrospectiva esa primera novela Los bogavantes?

AP: La novela que tiene todas esas paternidades, en todo caso tiene para mí una vibración secreta, de verdad humana, de furia. Son todas muy importantes porque tienen una vibración que es un poco nuestro mundo, 
que está desubicado; esa latinidad desubicada y periférica que somos nosotros y que se pone en evidencia cuando estamos en Europa o en Estados Unidos, cuando estamos en choque, cuando nos estamos confrontando con nuestra sensibilidad frente a una forma de vida que está organizada, que tal vez es superior como organización, pero que no nos conforma. Por eso Los bogavantes, para mí, es un libro de crisis, y por eso creo que es válido, y en ese sentido, menor; pero para mí lo único que cuenta es la literatura. Yo creo que lo único que cuenta es el lenguaje y el logro literario.

MGP: Siguiendo con la historia de tus libros, ¿qué tipo de novela es En la boca del tigre?

AP: Es una versión de la vida de los sudamericanos, pero en otro mundo, que para nosotros es completamente exótico, que es el mundo ruso. Es un poco lo mismo, porque si bien Los bogavantes es la historia de los latinoamericanos, el origen de los revolucionarios, los burgueses latinoamericanos en París, en ese París que ya es un hervidero que va a provocar el año 68, En la boca del tigre es un poco la otra confrontación de nuestra cultura, de nuestro universo, de nuestra sensibilidad con un mundo también muy poderoso, organizado y distinto como es el soviético. ¿Comprendes? Hice las dos cosas sin mucha voluntad. Eran necesidades interiores. Nunca lo había racionalizado. Después, con los años, me di cuenta de que entre los dos libros había una correspondencia secreta de búsquedas mías. Los libros te van revelando después de muchos años sus motivaciones, son muy raros, son como los gatos, que los comprendes después de mucho tiempo. Cuando los hiciste no sabes bien. La primera intención no es la cierta. Hay otros contenidos detrás de cada uno. Y después, los años te explican a vos mismo.

MGP: ¿Cómo llegas a concebir Daimón, tan distinta de las dos primeras? Sin duda hay un gran cambio y un gran salto cualitativo en tu escritura.

AP: Después de ocho años, ésa es mi gran ruptura. Después de ocho años de silencio, de aprendizaje y de reciclaje.

MGP: En esa novela hay un trabajo de investigación que funciona como subtexto de la narración, es decir, la documentación minuciosa de la historia.

AP: Daimón y Los perros del paraíso forman parte de una especie de trilogía que voy a terminar pronto, con la última novela, que se va a llamar Los heraldos negros, en homenaje a César Vallejo, sobre las misiones jesuíticas. En esas novelas ingresa el tema de lo histórico de una forma muy especial. Yo no me propuse escribir una novela histórica de ninguna manera. Voy más allá de la historia, a la metahistoria si quieres, para 
comprender nuestra época, para comprender nuestra raíz, nuestra ruptura, nuestra adolescencia eterna. Esas novelas exploran temas como el descubrimiento de América (Los perros del paraíso) y el conquistador loco (Daimón), que es Lope de Aguirre, el conquistador que nos queda a América, porque la idea de autoridad y poder en este continente nos viene del conquistador loco y no del conquistador santo; es la imagen que inventó España para poder soportar el genocidio. Por eso hay un juego de anacronismos constantes: el pasado y el presente están mezclados en un tiempo circular. Y, en efecto, incluso uno de los personajes llega a vivir cuatrocientos años.

Esas novelas me exigieron un gran trabajo historiográfico para manejar textos, para formar una visión de lo americano que no sea solamente la consabida visión política adocenada con categorías europeas y para hacer que la visión fuera estética, que fuera surgiendo desde el lenguaje y no desde las ideas. Fue un trabajo muy grande que me llenó de alegrías, pero que me costó mucho hacerlo. Investigué mucho en la personalidad de Lope de Aguirre en la historia de América, y lo mismo con el libro de Colón. Uno me llevó siete años y el otro cinco.

MGP: Sorprende al lector la cantidad de información que se maneja en esas novelas, junto con sus contradicciones.

AP: Tergiverso y creo fantasías en base a personajes históricos, pero en base a hechos ciertos o que pudieran metamorfosearse en una incertidumbre. Es decir, que hay una serie de juegos elípticos, sucesivos, de arabescos, o sea, el barroco. A mí me parece que la historia de América es como la selva de América. Si vos quieres ir de un punto a otro de la selva ya sabes que en línea recta no llegas. El barroco está consustanciado con la descripción topográfica y con la descripción histórica de América. La historia era, además, la historia oficial de América. La escribieron los conquistadores, los clérigos y después los penosos académicos fascistas. Hay que decirlo. En España no hubo revisionismo histórico. Recién ahora, en los últimos diez años, se están enterando de la historia. Somos nosotros, los americanos, los que hemos formado la conciencia del continente. Eso es de lo que culpo a los argentinos, que tan estúpidamente creen que tienen que hablar de la Argentina, y no se dan cuenta de que están en una organicidad humana, histórica, telúrica, que es el continente.

MGP: Dijiste hace un momento que la Argentina, y un poco Buenos Aires, es un círculo que encierra y no permite a la gente que está dentro ver más que los centros de Europa.

AP: Sí, porque les da muchas posibilidades literarias y prestigio. Es una esfera cerrada, que les obliga a ser ciegos. Yo me independicé de eso, y eso me constituye en un escritor marginal. Mis libros circulan a través 
de España y soy más conocido de repente en Francia. Ahora que el Premio Rómulo Gallegos me facilita doce traducciones en este momento, incluso la traducción al "porteño», la divulgación de mis libros se hará a mayor escala y llegará a un número más grande de lectores. En todo caso, yo me constituí en esta carrera mía, que la hice en el exterior, que la hice negando el medio de Buenos Aires, en cierta medida. Me constituí en una mezcla de renegado y marginal. Marginal porque yo no formo parte de los conceptos que tiene la gente sobre literatura en esta ciudad, y éste era el único medio que yo tenía. Después, la fibra esa americana en mí surgió con mucha fuerza, se hizo determinante y es la preocupación mayor de todo mi lenguaje, de mis libros, de mi estética. Esto me hizo que me separase un poco.

MGP: ¿Cómo te ha recibido Buenos Aires esta última vez, ya que acabas de regresar al país de tu última misión diplomática?

AP: Muy bien. Me han editado todos los libros. Me han dado premios. Acabo de recibir el Premio Esteban Echeverría, uno de los más importantes de Buenos Aires. Ahora me encuentro muy bien. La Editorial Emecé me hizo un contrato para reeditar todos mis libros, y ya lo están haciendo, casi dos libros por año.

MGP: Esto hacía mucha falta, porque varios de ellos están agotados. ¿Piensas que el público argentino está leyendo tu obra con interés?

AP: Sí, mucho. Fui el escritor que tal vez anduvo mejor el año pasado. Saqué dos libros, Los demonios ocultos y Los perros del paraíso, y los dos se agotaron en seguida, además de haber estado en la lista de bestsellers. Para mí, todo esto es novedoso. Pero creo que hay otro problema, y es que mis libros son demasiado «literarios», como sería el caso de Los perros del paraíso y Daimón, que es donde yo considero que está mi mayor esfuerzo.

MGP: Tal vez el más complicado de todos sea Los perros del paraíso, por el trabajo intrincado de lenguaje. Creo que Daimón se lee con más facilidad, y es un texto de importante calidad estética, con momentos de alta tensión poética en los fragmentos que describen la topografía y el ser americanos. Hay momentos de enorme vibración emocional.

AP: Traté de proceder en ese caso con un sentido expresionista del lenguaje. Mientras que el impresionismo es mejor cuando uno describe desde su lírica, el expresionismo es como el golpe que puede recibir una visión totalizante un observador general que no es uno. Hay un fenómeno de extrañamiento. Y yo quise reconstruir la sorpresa del hombre de Europa, del conquistador ante ese universo de América en formación: la catarata, el volcán, el bosque maravilloso, los nuevos pájaros. Tuve que recurrir a lo poético. 
MGP: Es un recurso muy bien desarrollado en tu narrativa, pues logra dar, en efecto, una visión nueva de América.

AP: Lo poético en la literatura hispanoamericana no es un sofisticado adorno de la prosa, como dicen algunos críticos europeos. Es simplemente el elemento necesario para nuestro realismo.

MGP: Ya lo han señalado Carpentier, Lezama Lima y García Márquez, entre otros. Al europeo le falta el referente americano para visualizar un río como el Urubamba de Daimón o de las novelas de Scorza. Estas dos novelas, Daimón y Los perros del paraíso, plantean una problemática bastante diferente de lo que plantea la escritura de Buenos Aires. Creo que habrá otros escritores argentinos que hallarán en tu narrativa un apoyo y un incentivo en tu obra.

En cuanto a tu última novela, Los demonios ocultos, recientemente publicada, hay otro registro, otra voz, otra visión; incluso a nivel de lenguaje es distinta.

AP: También ha tenido mucho éxito en España.

MGP: ¿A qué atribuyes ese éxito?

AP: Pienso que es otra manera de tratar el tema del nazismo. La mayoría toma este tema por el horror, pero no por lo que era, de sus motivaciones, ideologías y mitos que se movían detrás del horror. Entonces yo tuve que elegir entre el nazismo tradicional de los campos de concentración, del genocidio, del horror o el de la ideología. Esto último creo que es lo que interesó mucho. Además está escrita con un sentido bastante perverso, porque sin hablar de la Argentina y de América Latina, el autoritarismo nuestro está como haciendo puente a esa otra forma tremenda de represividad. Hay un juego de reflejos.

MGP: Sí, pero hay indicios importantes, como la figura de Perón y de Eva Perón.

AP: Es un juego de reflejos que van orientando al lector hacia unas sospechas, hacia una preocupación y que no está solucionado. Es otra cosa que yo traté de hacer. Generalmente, de una concepción ideológica de la novela, uno tiende a solucionar como se soluciona en las obras del teatro clásico. Pero a veces en ciertos temas lo mejor es la insolución; es dejar abiertas sugerencias, ciertos caminos, y no tocar más. Eso creo que hizo que el libro interesara tanto.

MGP: En esta novela continúa tu preocupación por el poder, la autoridad y la locura, que ya habías tratado en Daimón y en Los perros del paraíso.

AP: Sí, eso es el centro de mi trabajo. La tercera etapa es la novela que estoy escribiendo, Los heraldos negros. No está tomado históricamente, sino desde el choque de la metafísica europea con la mística animista 
de los tupi-guaraní, lo cual me da lugar a muchas diversiones y juegos literarios con la teología y la mitología de América, con las visiones cosmológicas, las visiones del paraíso. Es una novela bastante novelesca, porque se inicia en la historia de un jesuita joven que viene del Tirol y que desde allí pasa a Roma. Ahí lo convocan venir a este sueño que es crear la ciudad de Dios en la tierra, en la selva de América. El delirio de crear ciudades con pórticos de cemento en medio de la selva, que es lo que son esas misiones.

También terminé una novela que empecé a escribir hace muchos años. Es una novela sobre Buenos Aires, que ya está en prensa y que se llama La reina del Plata. Es muy rara, porque es un poco la explicación del tiempo circular, o sea, que el pasado es el futuro y el futuro es el pasado al mismo tiempo; ya no existe la diferencia. Es una novela en torno a los mitos de Buenos Aires, un Buenos Aires futuro, pero que contiene cosas del pasado porteño. Es una novela porteña en cierto modo.

MPG: Parece una novela muy imaginativa, y por la manera en que has hablado de ella, pienso que continúas manejando la ironía como el tono y estructuración dominantes, como en las anteriores.

AP: Sí, así es.

MPG: Sin embargo, en Los demonios ocultos la ironía tiene otro registro $\mathrm{y}$, en parte, desaparece. ¿Tuvo alguna influencia en la selección del tema tu estancia en Israel como diplomático?

AP: No. Ya la tenía escrita desde 1976, antes de ir a Israel, pero me faltaba llegar a hacer unas conexiones entre los contenidos míticos con la narración. Después surgió la idea de la búsqueda del padre. Ese hilo de conexión nace de la democracia, del exilio. Nace del exilio español, que es el más noble que hubo. El protagonista empieza a buscar y encuentra que su padre es un jerarca nazi.

MGP: La línea narrativa del padre queda abierta, como decías antes, y de ella podría pensarse en otra novela.

AP: Sí, es otra novela y ya está escrita. Es precisamente la versión del padre, que es como un símbolo del nazismo. Es decir, es un tema clásico de la novela. A partir de 1976 comencé a escribir partes, por eso es un poco discontinua, y hay mucha distancia de años entre el principio y el final. Creo que han quedado como saltitos.

MGP: ¿Hay en Lorca, el protagonista de Los demonios ocultos, un residuo autobiográfico?

AP: No y sí; inventé el personaje en base a mi experiencia personal, como es el haber vivido en las islas del Tigre cuando era bastante más joven. El arroyo Martínez, el Ibicuy, son los lugares que más me impresionaron. Reconstruí también un Buenos Aires que yo conocía, que era 
el Buenos Aires maravilloso del peronismo, cuando había dinero. Había bailes en «La Enramada», burdeles y nazis. Ese Buenos Aires, que era mucho más feliz y más divertido que éste. Fue el viaje a esos años de estudiante. En ese sentido te puedo decir que la primera parte de la novela, en lo que respecta a la reconstrucción de ese período, puede decirse que es autobiográfica.

MGP: La novela en la segunda parte toma un curso diferente, cuando el protagonista emprende la laberíntica búsqueda del padre, y acaba con el encuentro de Martin Bormann.

MGP: Sí, buscando al padre encuentra a Bormann. Algunos dicen que en la novela todo es lícito hasta llegar al borde de lo verosímil. Y es verosímil que un tipo, para saber dónde está su padre, tenga que buscar a un personaje como Bormann para preguntárselo. Si el único que se lo puede decir es Bormann, porque es la única persona que lo conoció, el protagonista tiene que hacer el viaje. Así es como se me ocurrió eso. Llegar al límite de lo novelesco: que este hombre de origen modesto de Buenos Aires, que vivía con unas tías españolas republicanas, tenga que viajar y buscar todo el trasfondo secreto del nazismo, llegar a un criminal de guerra y preguntarle dónde está su padre. Es verosímil; es el extremo de lo tolerable.

MGP: Creo que la peripecia de Lorca en pos de su padre está muy bien trabajada y que es verosímil. Pero cuando Martin Bormann sube al tambo del incario, de repente el lector escucha una carcajada estridente del narrador, y es inesperada, porque el manejo de la ironía, tan insidiosa en Daimón y Los perros del paraíso, no es parte del registro y la voz de Los demonios ocultos.

Pasando a tu obra por hacer, ¿cuáles son tus proyectos inmediatos?

AP: Resumiendo, hay una novela en la imprenta en Argentina y en España, La reina del Plata; tengo terminada la crónica del padre y estoy ya corrigiéndola. Espero terminarla este mes. Luego me dedicaré totalmente a hacer la tercera parte de la otra, con lo que cerraré el ciclo. Después no sé qué haré. Estoy sacando cosas que tengo de tiempo atrás. Yo escribía un libro cada cinco, cada siete años, así que tengo mucho material en mi escritorio. En este momento estoy definiendo todas las líneas que he trabajado. Estoy cerrando una etapa y creo que éste es un momento muy importante para mí. Por primera vez siento ganas de escribir. Antes me costaba enormemente. Ahora tengo ganas porque estoy como recorriendo líneas tiradas y echadas hace muchos años.

MGP: ¿Qué ha significado para vos ganar el Premio Rómulo Gallegos? 
AP: Ha significado reconocimiento. Yo era, como te decía, un escritor poco conocido y marginado. El premio me confirmó como escritor, y lo que me gusta más es ese reconocimiento secreto por el hecho literario. Yo siempre en esa soledad que tiene un escritor, y te hablo de veinte años de soledad, veinte años en distintos países con tu máquina de escribir y que ni un perro pase a saludarte. Yo siempre en esos años larguísimos que tiene todo escirtor, y que debe tenerlos para su depuración, para su asentamiento de ideas, para su refinamiento, yo siempre pensaba que había que confiar en lo literario, porque en última instancia, en este tráfago, en esta enorme cantidad de mentira escrita, de tontería, de vanidad, de novelistas, de pronto sos reconocido mundialmente. Pienso en la experiencia de un Borges o un Lezama Lima, este cubano que ni siquiera alcanza a publicar su novela es el que pasa a primer plano. Hay un aliento final de lo literario. Si vos te das totalmente al ángel de lo literario, a la pasión real de la creación del lenguaje, eso te va a pagar en algún momento.

Y yo, que estaba totalmente marginalizado, lo sentí cuando me premiaron Los perros del paraíso, porque yo tuve que competir con Camilo José Cela, con Bryce Echenique, con Sábato y con otros grandes escritores. Me di cuenta de que hay un reconocimiento del esfuerzo del lenguaje, que no es ni la historia, ni es el tema, ni es el exotismo ni la conveniencia, ni la política que tengas. En el fondo, en este mar lleno de mentira de la literatura, hay ciertos pilares que se van refinando y afirmando con el tiempo, y son de calidad. Eso es lo que permite que la literatura sea un fenómeno mundial.

MGP: Dijiste hace un momento que tu estancia en el Perú cambió drásticamente la visión del mundo para vos.

AP: Sí. Cambió la visión de América que puede tener un escritor porteño, argentino.

MGP: ¿Qué piensas que produjo esa transformación de tu visión?

AP: Vi la realidad de América por primera vez en toda su profundidad. Porque incluso en la Argentina, por un nivel de vida más alto, no lo ves; pero sobre todo encontré una vieja civilización, que es la civilización incaica. Había un elemento cultural, una impresionante postergación de una civilización anonadada, usando el lenguaje de Toynbee, que había recibido el impacto y que está como a la espera, y que tiene el coraje de no haber abandonado sus valores, no haber ingresado en la afasia de la vida de la transculturalización que se le propuso siempre, sobre todo en el siglo XIX, con la independencia de América.

Es un universo lleno de contenidos, de profundidades, de misterio del mundo inca. El mundo andino fue para mí un tremendo agregado de 
riquezas espirituales, de nuevas cosas. Me dediqué hasta a la arqueología. Leí muchísimos estudios antropológicos sobre los indios, su mitología, y eso forma parte de mis libros, porque está como integrada la visión de los vencidos. Por eso yo digo que en 1492, el día 12 de octubre, fueron ios americanos los que descubrieron Europa. Trato de legitimizar, dando vuelta la frase, lo que significó para ellos culturalmente. 